\title{
EXTRINSIC POLYPEPTIDES OF THE CHLOROPLAST OXYGEN EVOLVING COMPLEX CONSTITUTE THE TETRAMERIC ESS PARTICLES OF HIGHER PLANT THYLAKOIDS
}

\author{
by \\ DAVID J. SIMPSON and BERTIL ANDERSSON ${ }^{1)}$ \\ Department of Physiology, Carlsberg Laboratory, \\ Gamle Carlsberg Vej 10, DK-2500 Copenhagen Valby \\ "Department of Biochemistry, Arrhenius Laboratory, \\ University of Stockholm, S-10691 Stockholm
}

Keywords: Electron microscopy, freeze-etch, reconstitution, spinach

\begin{abstract}
Inside-out vesicles derived from grana partition regions of spinach thylakoids were isolated by Yeda press treatment followed by aqueous polymer phase partitioning. Their structure was examined by freeze-etch electron microscopy, which revealed numerous tetrameric particles on their outer surface, corresponding to the ESs particles of the lumenal surface of intact thylakoids. The vesicles were treated with several different salt washes which specifically removed some or all of the extrinsic polypeptides of the oxygen evolving complex. Removal of the 16 and $23 \mathrm{kD}$ extrinsic polypeptides with $\mathrm{NaCl}$ caused a reduction in the surface relief or loss of the tetrameric structure of the ESs particles. When the $33 \mathrm{kD}$ polypeptide was removed in addition to the 16 and $23 \mathrm{kD}$ polypeptides, either by washing with $\mathrm{CaCl}_{2}$ or alkaline Tris, the particles could no longer be clearly resolved from the membrane surface. Vesicles washed with $1 \mathrm{M}-\mathrm{CaCl}_{2}$ were reconstituted with a 10 -fold excess of a crude extract containing the extrinsic polypeptides of the oxygen evolving complex. This resulted in the reappearance of particles on the membrane surface, although they did not have a clear tetrameric structure. Thus the extrinsic polypeptides of the oxygen evolving complex are the major components of the tetrameric ESs particles of thylakoids.
\end{abstract}

\section{INTRODUCTION}

A characteristic feature of higher plant thylakoids is the presence of particles with a tetrameric structure of the inner surface of grana partition regions $(21,26)$. They are revealed by freeze-etching and are designated ESs particles using the terminology of STAEHELIN (25), and correspond to the quantosomes of PARK and BIGGINS (20). They are the surface projections of the membrane spanning EFs particles which, under certain circumstances $(13,14)$ form ordered arrays. The correspondence between EFs and ESs arrays enabled this correlation to be established (14).

The composition of the EFs/ESs particle has been the subject of several papers. The first suggestion that they were the structural counterpart of photosystem II came from the digitonin fractionation studies of ARNTZEN et al. (7). This was substantiated by quantitative analysis of the

Abbreviations: $\mathrm{Chl}$ = chlorophyll; $\mathrm{DCMU}=3$-(3,4-dichlorophenyl)-1, 1-dimethyl urea; $\mathrm{EFs}=$ endoplasmic fracture face of stacked thylakoids; ESs = endoplasmic surface of stacked thylakoids; LHCII = light-harvesting chlorophyll production of photosystem II; Mes = 2-(N-morpholino)ethanesulphonic acid; PFs = protoplasmic fracture face of stacked thylakoids; Tris $=$ tris(hydroxymethyl)aminomethane. 
numbers and sizes of particles in stacked and re-stacked thylakoids (25). Indirect evidence, based on the loss of EFs particles in photosystem II mutants $(15,23)$, further indicated that EFs particles contain the reaction centre of photosystem II. Examination of a barley mutant lacking $\mathrm{Chl} b$ and $\mathrm{LHCII}$, in which the EFs particles were reduced in size, led to the suggestion that EFs particles normally contain LHCII, the major light-harvesting chlorophyll-protein of thylakoids (16). This model was extended by ARMOND et al. (6), who followed the greening of pea grówn under intermittent light and then transferred to continuous light. They reported a stepwise increase in EF particle size, which they explained by the addition of 1,2 or 4 subunits of LHCII. Their model indicates that LHCII extends into the thylakoid lumen and presumably forms part of the 4 subunits of the tetrameric ESs particle. The $\mathrm{Chl} b$-less barley mutant contains tetrameric ESs particles $(16,22)$, but they are significantly smaller than those of wild type thylakoids. A re-examination of this mutant led to the proposal that LHCII is located in PFs particles, and that the reduction in EFs and ESs particle size was postulated to be due to the loss of other Chl $a / b$-binding proteins (22). This has recently been supported by the freeze-fracture analysis of the $\mathrm{Oy}$-yg maize mutant (10). These authors suggest that changes in EFs particle size reflect differences in the content of $\mathrm{Chl}_{a / b}-\mathrm{Pl}$ ( = CP29).

Further information about the composition of the EFs/ESs particle has come from studies of $\mathrm{Mn}^{++}$deficiency and thylakoid composition. Manganese deficiency, which causes the reversible loss of three-quarters of the EFs and ESs particles (24), is also associated with the loss of oxygen evolution and DCMU-binding sites (9). This indicates that these particles contain not only the reaction centre of photosystem II, but the electron transport components between the oxygen evolving complex and the DCMU-binding protein $\mathrm{D} 1$. In this communication, using salt washing of mechanically isolated inside-out vesicles derived from thylakoid membranes (5) capable of oxygen evolution (11), we present evidence that the tetrameric ESs particles are composed of the extrinsic polypeptides of the oxygen evolving complex.

\section{MATERIALS AND METHODS}

\subsection{Isolation of inside-out thylakoid vesicles}

Spinach thylakoids were isolated under stacking conditions as described by ÅKERLUND et al. (29). Prior to fragmentation, the thylakoid membranes were suspended in $10 \mathrm{~mm}$-sodium phosphate $\mathrm{pH} 7.4,5 \mathrm{mM}-\mathrm{MgCl}_{2}$ and $100 \mathrm{mM}$-sucrose, and passed twice through a Yeda press at a pressure of $10 \mathrm{MPa}$ (1). Immediately afterwards, $5 \mathrm{~mm}$-EDTA was added to de-stack the thylakoids, and the homogenate was passed twice more through the Yeda press. Starch and residual unfragmented thylakoids were removed by centrifugation at $1000 \times \mathrm{g}$ for $10 \mathrm{~min}$. $1 \mathrm{ml}$ of the suspension ( $4 \mathrm{mg} \mathrm{Chl} \cdot \mathrm{ml}^{-1}$ ) was added to $24 \mathrm{~g}$ of the polymer solution, yielding a phase system of the following composition: $5.55 \%$ dextran T-500, 5.55\% polyethyleneglycol 3350 (previously named 4000 ), 10 mM-sodium phosphate $\mathrm{pH} 7.4,5 \mathrm{~mm}-\mathrm{NaCl}$ and $20 \mathrm{~mm}$-sucrose (1). The phase system was carefully mixed at $3{ }^{\circ} \mathrm{C}$ and allowed to settle. The lower phase $\left(B_{1}\right)$ was collected and repartitioned with fresh upper phase, yielding fraction $B_{2}$. The repartitioning of the lower phase was continued until fraction $\mathrm{B}_{5}$ was obtained. The vesicles of this fraction were centrifuged at $100,000 \times \mathrm{g}$ for 30 min and suspended in $500 \mathrm{~mm}$-sucrose, $5 \mathrm{~mm}$ sodium phosphate $\mathrm{pH} 6.5$ and $2.5 \mathrm{~mm}-\mathrm{NaCl}$.

\subsection{Specific removal of extrinsic polypeptides}

The inside-out vesicles (fraction $B_{5}$ ) were washed in different media to specifically remove extrinsic polypeptides from the inner thylakoid surface (ES) (2). The wash media were: 0.25 $\mathrm{mm}-\mathrm{NaCl}, 10 \mathrm{~mm}-\mathrm{Mes} \mathrm{pH} 6.5 ; 1 \mathrm{M}-\mathrm{NaCl}, 10$ mM-Mes pH 6.5; 1 M-CaCl, 10 mM-Mes pH 6.5 and $0.8 \mathrm{M}$-Tris $\mathrm{pH} 8.4$.

The thylakoids $\left(200 \mu \mathrm{g} \mathrm{Chl} \cdot \mathrm{ml}^{-1}\right)$ were incubated in the appropriate medium for $30 \mathrm{~min}$, pelleted by centrifugation at $100,000 \times \mathrm{g}$ for 30 min, and finally suspended in $5 \mathrm{mM}-\mathrm{MgCl}_{2}, 10$ mM-Mes pH 6.5. The control thylakoids were washed in $5 \mathrm{~mm}-\mathrm{MgCl}_{2}, 10 \mathrm{~mm}$-Mes pH 6.5 .

An extract of water soluble thylakoid proteins was prepared from acetone treated thylakoids as previously described (29). For the reconstitution experiments, washed inside-out vesicles were incubated with the crude protein extract at a 

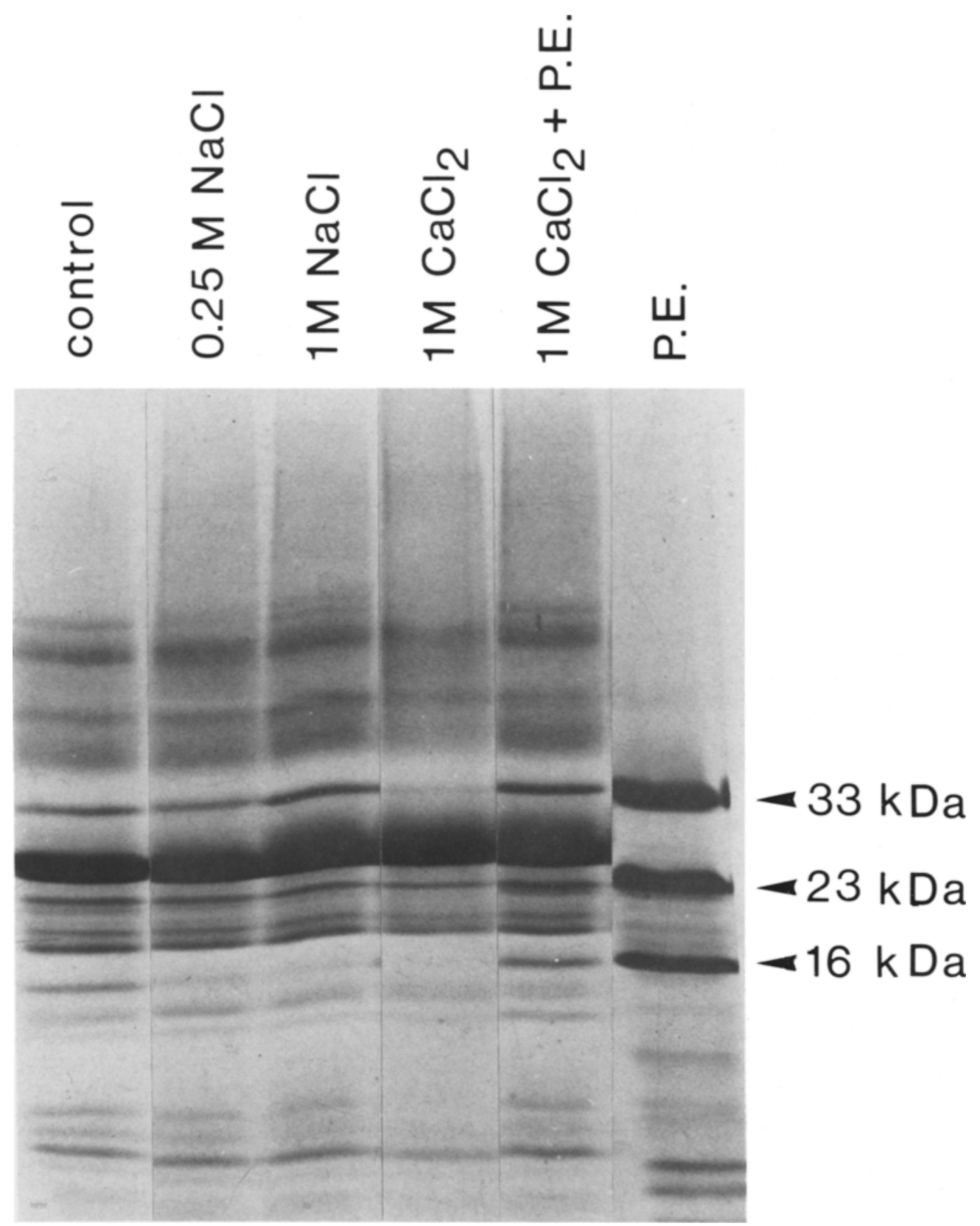

Figure 1. Polypeptide composition of inside-out vesicles derived from grana partitions. The 33,23 and $16 \mathrm{kD}$ polypeptides of the untreated thylakoids (control lane) are extrinsic components of the oxygen evolving complex. Two or all three of these are removed by the salt wash treatments indicated. P.E. = protein extract used for the reconstitution experiment analysed in the second lane from the right. 

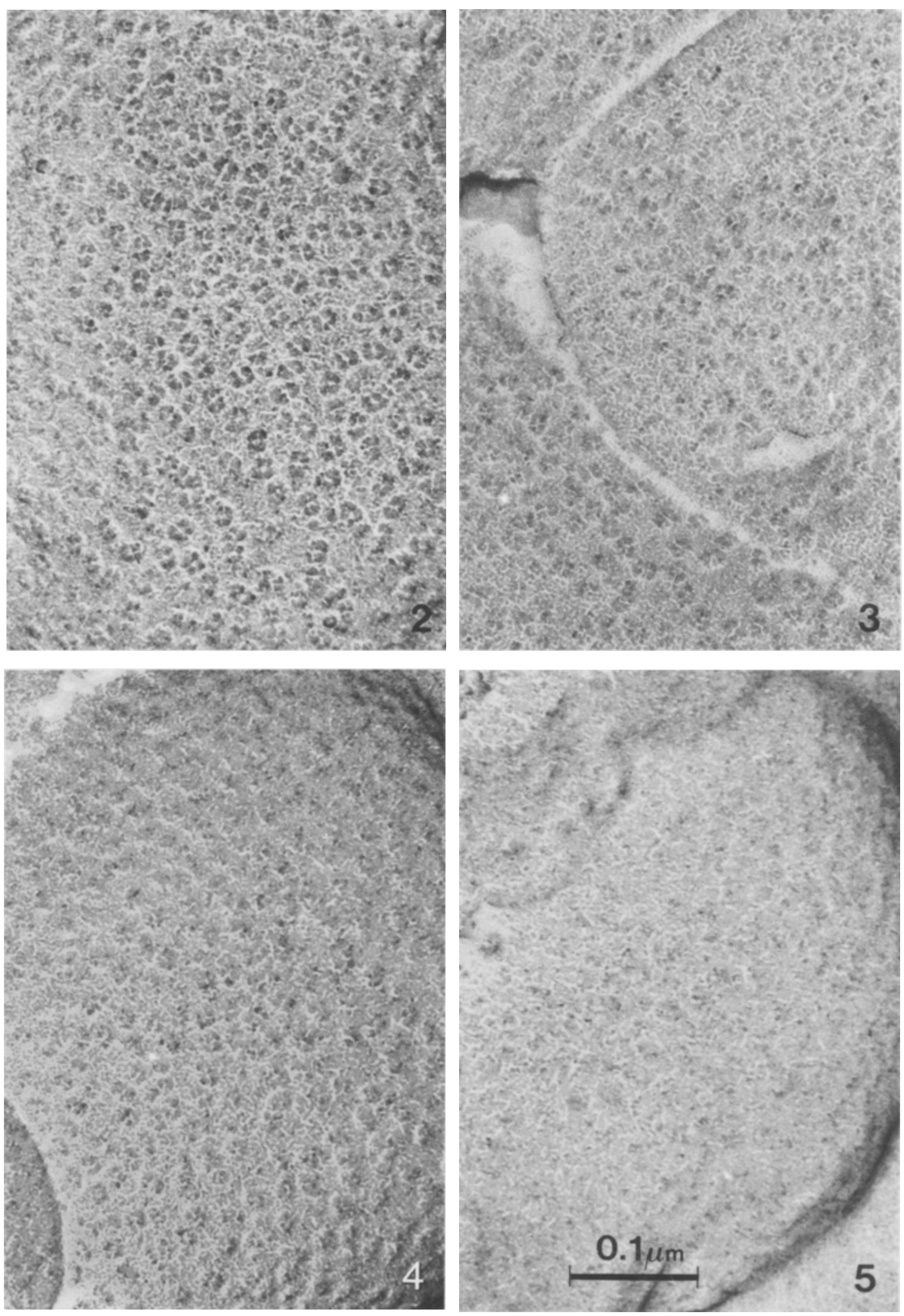

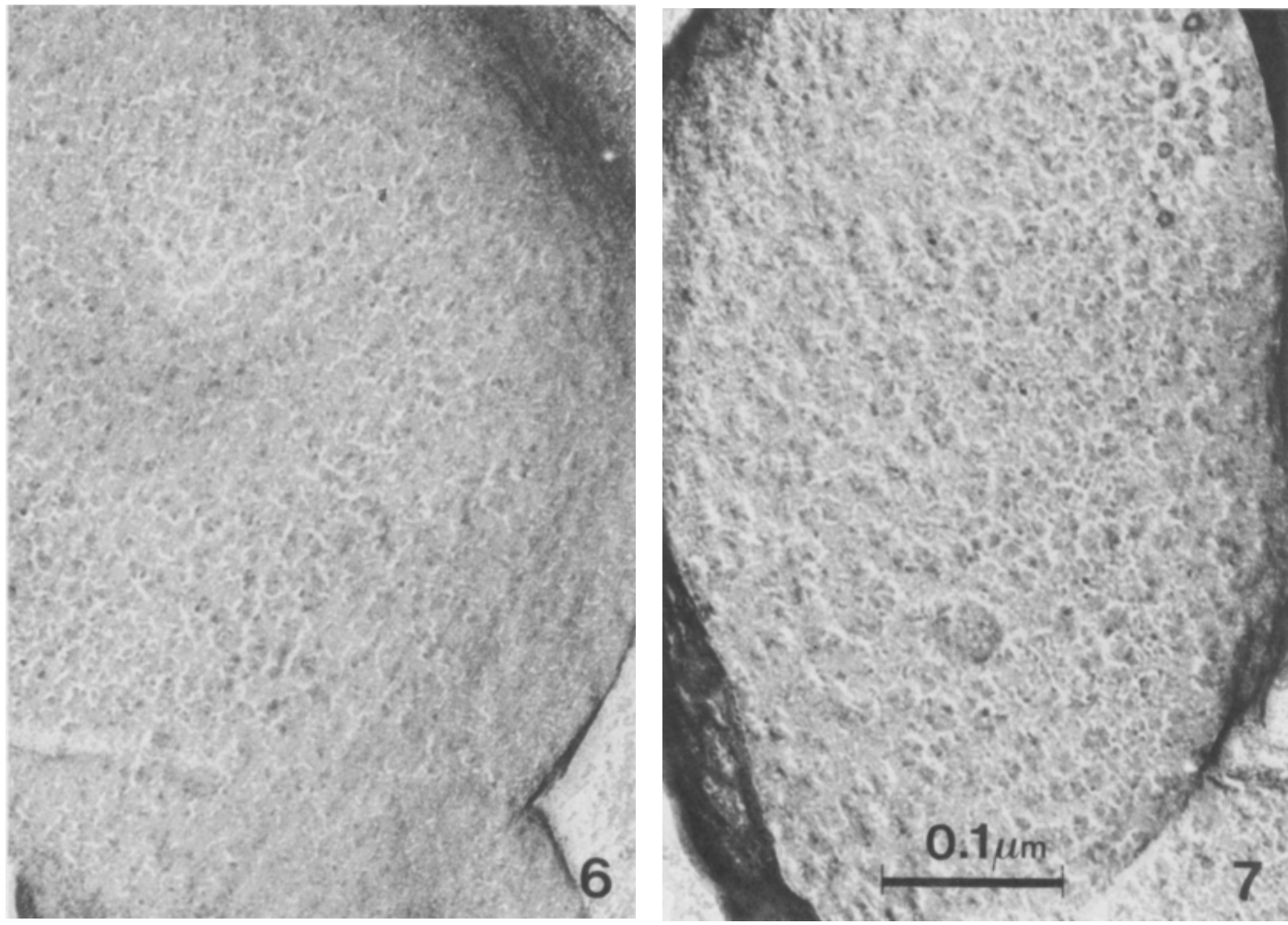

Figure 2. Ultrastructure of the surface of untreated inside-out vesicles revealed by freeze-etch electron microscopy. The tetrameric particles are the ESs particles of thylakoid membranes. Magnification $\times 200,000$.

Figure 3. Appearance of inside-out vesicles after washing with $0.25 \mathrm{M}-\mathrm{NaCl}$. The particles have a tetrameric appearance, but a lower surface relief than the control, correlated with the loss of the $16 \mathrm{kD}$ polypeptide, and partial loss of the $23 \mathrm{kD}$ polpeptide. Magnification $\times 200,000$.

Figure 4. Removal of the 16 and $23 \mathrm{kD}$ polypeptides with $1 \mathrm{M}-\mathrm{NaCl}$ causes a loss of the tetrameric structure, but particles are still resolvable on the membrane surface. Magnification $\times 200,000$.

Figure 5. Removal of the $16,23,33$ and most of the $10 \mathrm{kD}$ extrinsic polypeptides by washing with alkaline Tris, produces an almost featureless membrane surface on the inside-out vesicles. Magnification $\times 200,000$.

Figure 6. Washing with $1 \mathrm{M}-\mathrm{CaCl}_{2}$ removes the 16,23 and $33 \mathrm{kD}$ polypeptides and particles can no longer be clearly seen on the membrane surface. Magnification $\times 200,000$.

Figure 7. Reconstitution of vesicles washed with $1 \mathrm{M}-\mathrm{CaCl}_{2}$ using a crude protein extract of extrinsic thylakoid polypeptides, results in the reappearance of numerous particles. They do no appear to have a tetrameric fine structure, which may explain the low degree of functional reconstitution. Magnification $\times 200,000$.

Table I. Extrinsic polypeptides removed by salt washing of thylakoids*

\begin{tabular}{|c|c|c|c|c|}
\hline \multirow[b]{2}{*}{ Treatment } & \multicolumn{4}{|c|}{ Percent remaining } \\
\hline & 10 & 16 & 23 & $33(\mathrm{kD})$ \\
\hline $0.25 \mathrm{M}-\mathrm{NaCl}, \mathrm{pH} 6.5$ & 100 & 15 & 30 & 100 \\
\hline $1 \mathrm{M}-\mathrm{NaCl}, \mathrm{pH} 6.5$ & 100 & 0 & 0 & 100 \\
\hline $1 \mathrm{M}-\mathrm{CaCl}_{2}, \mathrm{pH} 6.5$ & 98 & 0 & 0 & 0 \\
\hline 0.8 M-Tris, pH 8.4 & 40 & 0 & 0 & 0 \\
\hline
\end{tabular}

* compiled from ref. 2 and 29 
protein : chlorophyll ratio of $10: 1$. The vesicles were subsequently centrifuged at $100,000 \times \mathrm{g}$ for $30 \mathrm{~min}$ and resuspended in $5 \mathrm{~mm}-\mathrm{MgCl}_{2}, 10$ mM-Mes pH 6.5. SDS-PAGE was performed as described by ÅKERLUND et al. (29).

\subsection{Electron microscopy}

The inside-out vesicles suspended in $5 \mathrm{~mm}-$ $\mathrm{MgCl}_{2}, 10 \mathrm{~mm}-\mathrm{Mes}, \mathrm{pH} 6.5$, at a concentration of 4-6 mg Chl $\cdot \mathrm{ml}^{-1}$ were pipetted onto gold planchettes and frozen in liquid Freon 22 cooled by liquid nitrogen. Samples were freeze-fractured at $-100{ }^{\circ} \mathrm{C}$ in a Balzers 301 freeze-etch apparatus, and deep-etched for $2 \mathrm{~min}$. The etched surface was replicated by rotary shadowing with $\mathrm{Pt} / \mathrm{C}$ at an angle of $22.5^{\circ}$ to a depth of $20 \AA$ (22). After carbon deposition, replicas were cleaned for at least $2 \mathrm{~h}$ in conc. sodium hypochlorite, washed in water and left overnight in diluted chromesulphuric acid. Replicas were then washed 4 times in distilled water, transferred to flamed 200 mesh copper grids and examined in a Siemens 102 electron microscope operated at $80 \mathrm{kV}$. Membrane areas for micrography were carefully selected for optimal shadowing to ensure the best possible resolution of surface particles.

\section{RESULTS AND DISCUSSION}

The outer surface of untreated inside-out spinach thylakoid vesicles was covered with numerous particles which had a tetrameric structure (Figure 2). These are the ESs particles of normal thylakoids, and their high density reflects a minimal degree of de-stacking during the improved isolation procedures $(1,11)$. It was important to wash these vesicles with the 5 $\mathrm{mM}-\mathrm{MgCl}_{2}, 10 \mathrm{~mm}-\mathrm{Mes}, \mathrm{pH} 6.5$ buffer to remove the aqueous polymer, otherwise no particles could be discerned on the membrane surface. We attribute this to the binding of polymer to the thylakoid surface, where it forms a thin, non-etchable layer.

Untreated thylakoids were subjected to a number of salt washes to remove selectively one or more of the extrinsic polypeptides of the oxygen evolving complex. The polypeptide composition of the control and treated vesicles is shown in Figure 1, and the polypeptides removed by the different treatments are tabulated in Table $I$.

The mildest treatment was washing with 0.25 $\mathrm{M}-\mathrm{NaCl}$, which removed the $16 \mathrm{kD}$ and some of the $23 \mathrm{kD}$ polypeptide (Table I). The surface of vesicles treated in this way was covered with particles with a definite tetrameric structure, but a slightly reduced surface relief (Figure 3 ). More complete removal of the 16 and $23 \mathrm{kD}$ polypeptides with $1 \mathrm{M}-\mathrm{NaCl}$ caused a loss of a clearly defined substructure, although particles were readily seen on the endoplasmic surface (ES) (Figure 4). When control inside-out thylakoid vesicles were washed with $1 \mathrm{M}-\mathrm{CaCl}_{2}$, which removed not only the 16 and $23 \mathrm{kD}$ extrinsic polypeptides, but also the $33 \mathrm{kD}$ polypeptide, the particles had almost completely disappeared (Figure 6). The surface of such vesicles was not completely smooth, but the particles had no clear substructure and were difficult to discern from the background. Washing with alkaline Tris, which removed the same polypeptides as 1 $\mathrm{M}-\mathrm{CaCl}_{2}$, plus most of a $10 \mathrm{kD}$ polypeptide (12), had a very similar effect (Figure 5), and it was difficult to distinguish between the two treatments in terms of ultrastructure (compare Figures 5 and 6).

Reconstitution of oxygen evolving capacity by the addition of purified extrinsic polypeptides has been demonstrated for $\mathrm{NaCl}$-washed $(18,29)$ and $\mathrm{CaCl}_{2}$-washed thylakoids (19). Since $\mathrm{CaCl}_{2}$-washed thylakoids showed a greater ultrastructural difference, they were used for reconstitution, using a crude extract of extrinsic polypeptides (29). This resulted in the reappearance of particles on the endoplasmic surface (ES) (Figure 7). Although the density of these particles was close to that of the control membranes, a tetrameric substructure could not be resolved. $\mathrm{CaCl}_{2}$ washed vesicles prepared by Triton X-100 treatment have been reconstituted with the $33 \mathrm{kD}$ polypeptide, but showed only $28 \%$ of the oxygen evolving capacity of control membranes (19). It is possible that a sequential addition of the 33,23 and $16 \mathrm{kD}$ polypeptides may have restored tetrameric particles and a more complete oxygen evolving capacity. Tris washing of photosystem II membranes isolated by Triton X-100 (8) did not remove the ESs 


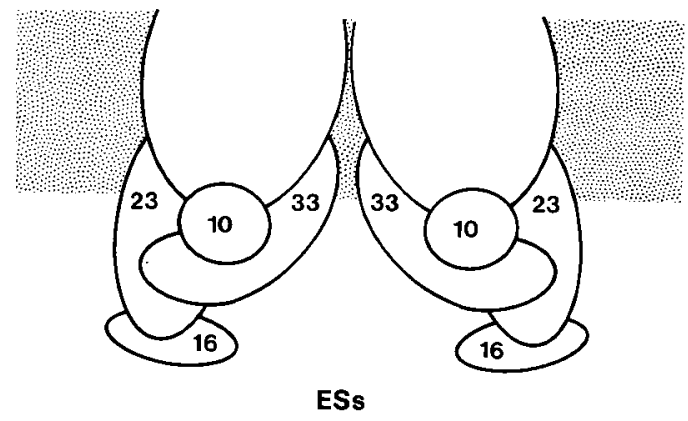

Figure 8. Model of the arrangement of the extrinsic polypeptides of the oxygen evolving complex. The symmetric changes in ESs particles as polypeptides are removed indicate that there are two sets of the polypeptides in each half of the $130 \times 195 \AA$ particle. The identity of the intrinsic polypeptides to which they bind is still: uncertain.

particles, in contrast with mechanically isolated grana vesicles (VALLON and SimPSON, unpublished data). Similar results have been reported by STAEHELIN et al. (27), and may reflect structural differences induced by lipid depletion of these membranes. This is supported, for example, by the greater accessibility at the inner membrane surface, of antibodies to chlorophyllproteins close to the photosystem II reaction centre in detergent isolated membranes compared with those isolated mechanically (28).

Selective removal of extrinsic polypeptides of the oxygen evolving complex by salt washing of inside-out thylakoid vesicles results in a progressive loss of material from the ESs tetrameric particles. This loss is dependent on which polypeptides are removed, and can be so extensive that the particles virtually disappear. The most significant changes in ESs particle ultrastructure were associated with the removal of the 23 and $33 \mathrm{kD}$ polypeptides. Loss of the $23 \mathrm{kD}$ polypeptide was linked to the disappearance of a tetrameric substructure, and when the $33 \mathrm{kD}$ polypeptide was removed as well, the particles could no longer be clearly resolved. These results show that the ESs tetramers are composed of the extrinsic polypeptides of the oxygen evolving complex. Although parts of the LHCII polypeptides can be recognised by antibodies at the inner thylakoid surface (3), our results indicate that
LHCII is not a component of ESs tetramers.

Quantitation of the extrinsic oxygen evolving complex polypeptides by rocket immunoelectrophoresis, has shown that there is one copy of each per $200 \mathrm{Chl}$ in intact spinach chloroplasts (4). This gives a stoichiometry of 2 copies of each per photosystem II reaction centre, assuming $400 \mathrm{Chl}$ per photosystem II reaction centre, although a stoichiometry of $1: 1$ has also been suggested (17). A feature of all the washing treatments was that the ESs particle ultrastructure changed symmetrically. This particle, which is $130 \times 195 \dot{A}(22)$ has a major groove across the long axis, dividing it in half. This is particularly clear when ESs particles form arrays. We suggest that each half of the ESs particle contains a set of the extrinsic oxygen evolving complex polypeptides. This is shown schematically in Figure 8, which is an attempt to incorporate the ultrastructural and re-binding data into a consistent model.

\section{ACKNOWLEDGEMENTS}

We thank Professor Diter vON WeTtSTEIN for critically reading the manuscript and Ms SOPHIE BINGSMARK for expert technical assistance. BERTIL ANDERSSON acknowledges financial support from the Swedish Research Council.

\section{REFERENCES}

1. ANDERSSON, B: Isolation of inside-out thylakoid vesicles with increased photosystem II purity Lateral index of thylakoid components. In: Adv. Photosyn. Res. (C. Sybesma, ed. ) Martinus Nijhof/Dr W. Junk. The Hague, vol. 3, pp. 223-226 (1984)

2. ANDERSSON, B.: Proteins participating in photosynthetic water oxidation. In: Encycl. Plant Physiol. (L. A. Staehelin \& C. J. Arntzen, eds.). Springer-Verlag, Berlin, Heidelberg, New York, vol. 19, pp. 447-456 (1986)

3. ANDERSSON, B., J. M. ANDERSON \& I. J. RYRIE: Transbilayer organization of the chlorophyllproteins of spinach thylakoids. Eur. J. Biochem. 123, 465-472 (1982)

4. ANDERSSON, B., C. LARSSON, C. JANSSON, U. LuUnGBERG \& H. -E: ÁKERLUND: Immunological studies on the organization of proteins in photosynthetic oxygen evolution. Biochim. Biophys. Acta 766, 21-28 (1984) 
5. ANDERSSON, B., D J. SiMPSON \& G. HØYER-HANSEN: Freeze-fracture evidence for the isolation of insideout spinach thylakoid vesicles. Carlsberg Res. Commun. 43, 77-89 (1978)

6. Armond, P. A., L. A. Staehelin \& C. J. Arntzen: Spatial relationship of photosystem I, photosystem II and the light-harvesting complex in chloroplast membranes. J. Cell Biol. 73, 400-418 (1977)

7. arntzen, C. J., R. A. Dilley \& F. L. Crane: A comparison of chloroplast membrane surfaces visualized by freeze-etch and negative-staining techniques; and ultrastructural characterization of membrane fractions obtained from digitonintreated spinach chloroplasts. J. Cell Biol. 43, 16-31 (1969)

8. BerThOLd, D. A., G. T. BABCOCK \& C. F. YOCUM: A highly resolved, oxygen-evolving photosystem II preparation from spinach thylakoid membranes. BPR and electron transport properties. FEBS Lett. 134, 231-234 (1981)

9. Cheniae, G. M. \& I. F. Martin: Site of manganese function in photosynthesis. Biochim. Biophys. Acta 153, 819-837 (1968)

10. Greene, B. A., D. R. AllRed, D. T. Morishige \& L. A. STAEHELIN: A light-sensitive photoregulatory mutant in maize deficient in LHCI and the "mobile" chlorophyll a/b LHCII. Abstr. VII Internat. Photosyn. Cong., Providence. no. 305-133 (1986)

11. Henry, L. E. A. \& B. L. Møller: Polypeptide composition of an oxygen evolving photosystem II vesicle from spinach chloroplasts. Carlsberg Res. Commun. 46, 227-242 (1981)

12. LJUNGBERG, U., H. -E. ÄKERLUND \& B. ANDERSSON: The release of a 10-kDa polypeptide from everted photosystem II thylakoids by alkaline Tris. FEBS Lett. 175, 255-258 (1984)

13. Machold, O., D. J. Simpson \& G. HøYer-HANSEN: Correlation between the freeze-fracture appearance and polypeptide composition of thylakoid membranes in barley. Carlsberg Res. Commun. 42, 499-516 (1977)

14. MilLER, K. R.: A particle spanning the photosynthetic membrane. J. Ultrastruct. Res. 54, 159-167 (1976)

15. Miller, K. R. \& R. A. Cushman: A chloroplast membrane lacking photosystem II. Thylakoid stacking in the absence of the photosystem II particle. Biochim. Biophys. Acta 546, 481-497 (1979)

16. MilleR, K. R., G.J. Miller \& K. R. MCINTYRE: The light-harvesting chlorophyll-protein complex of photosystem II. Its location in the photosynthetic membrane. J. Cell Biol. 71, 624-638 (1976)

17. Murata, N., M. Miyao, H. Matsunami \& T.
KUWABARA: Stoichiometry of components in the photosynthetic oxygen evolving system of photosystem II particles prepared with Triton X-100 from spinach chloroplasts. Biochim. Biophys. Acta $765,363-369$ (1984)

18. MøLler, B. L. \& P. B. HøJ: A thylakoid polypeptide involved in the reconstitution of photosynthetic oxygen evolution. Carlsberg. Res. Commun. 48, 161-185 (1983)

19. ONO, T. -A. \& Y. INOUE: Reconstitution of photosynthetic oxygen evolving capacity by rebinding of $33 \mathrm{kDa}$ protein to $\mathrm{CaCl}_{2}$-extracted PSII particles. FEBS Lett. 166, 381-384 (1984)

20. PARK, R. B. \& J. Biggins: Quantasome: size and composition. Science 144, 1009-1011 (1964)

21. PARK, R. B. \& A. O. PFeIFFHOFER: Ultrastructural observations on deep-etched thylakoids. J. Cell Sci. 5, 299-311 (1969)

22. Simpson, D. J.: Freeze-fracture studies on barley plastid membranes. III Location of the light-harvesting chlorophyll-protein. Carlsberg Res. Commun. 44, 305-336 (1979)

23. Simpson, D. J., G. Høyer-Hansen, N.-H.Chua \& D. VON WETTSTEIN: The use of gene mutants in barley to correlate thylakoid polypeptide composition with the structure of the photosynthetic membrane. Proc. Fourth Internat. Photosyn. Cong., Reading pp. 537-548 (1977)

24. Simpson, D. J. \& S. P. RoBINSON: Freeze-fracture ultrastructure of thylakoid membranes in chloroplasts from manganese-deficient plants. Plant Physiol. 74, 735-741 (1984)

25. Staehelin, L. A.: Reversible particle movements associated with unstacking and restacking of chloroplast membrane in vitro. J. Cell Biol. 71, 136-158 (1976)

26. Staehelin, L. A., P. A. ARmond \& K. R. Miller: Chloroplast membrane organization at the supramolecular level and its functional implications. Brookhaven Symp. Biol. 28, 278-315 (1976)

27. Staehelin, L. A., M. DeWit \& M. Seibert: Structural identification of the oxygen-evolving apparatus on the lumenal surface of freeze-etched thylakoid membranes. Proc. VII Internat. Cong. Photosyn., Providence, in press (1986)

28. VALLON, O., F. A. WollmaN \& J. Olive: Immunocytochemical studies on the organization of thylakoid proteins. Proc. VII Internat. Cong. Photosyn., Providence, in press (1986)

29. Ä́kerLund, H. -E., C. JansSon \& B. ANDERsSon: Reconstitution of photosynthetic water splitting in inside-out thylakoid vesicles and identification of a participating polypeptide. Biochim. Biophys. Acta 681, 1-10 (1982)

Accepted by S.O. ANDERSEN 